\title{
Caracterización de los Recursos tróficos utilizados POR APIS MELLIFERA L. EN UN ÁREA DE LAS YUNGAS EN EL NORTE dE SAlta (ARgentina)
}

\author{
Characterization of the trophic Resources used by ApIS melliferA \\ L. IN AN AREA OF THE Yungas IN THE NORTH OF SAlta (ARgentina)
}

Magali Verónica Méndez ${ }^{1 *}$ D, Ana Carina Sánchez ${ }^{1}$ [D y Liliana Concepción Lupo ${ }^{1}$

1. Instituto de Ecorregiones Andinas (INECOA), Universidad Nacional de Jujuy - CONICET, Facultad de Ciencias Agrarias, Laboratorio de Palinología. Alberdi 47, C. P. 4 600, S. S. de Jujuy, Argentina.

*magalivmendez@fca.unju.edu.ar

Citar este artículo

MÉNDEZ, M. V., A. C. SÁNCHEZ \& L. C. LUPO. 2021. Caracterización de los recursos tróficos utilizados por Apis mellifera L. en un área de las Yungas en el norte de Salta (Argentina). Bol. Soc. Argent. Bot. 56: 171-185.

DOI: https://doi. org/10.31055/1851.2372.v56. n2.29926

Recibido: 28 May 2020 Aceptado: 28 Abr 2021

Publicado en línea: 10 Jun 2021

Publicado impreso: 30 Jun 2021

Editor: Gonzalo Márquez

ISSN versión impresa 0373-580X ISSN versión on-line 1851-2372

\section{SUMMARY}

Background and aims: The main trophic resources used by honeybees are nectar and pollen, being the source of carbohydrates and protein for the hive, respectively. In this context, to determine the relationship between bees and floral resources, melisopalynological studies are carried out to identify the different plants that contribute to the bees' diet.

M\&M: The samples were obtained from beehives of producers in the locality of Los Toldos (Salta): immature honey samples were extracted with $10 \mathrm{ml}$ sterilized syringes and corbicular pollen samples were extracted through pollen hunting traps placed in the taphole of the beehives for 24 hours. All samples were processed by standard techniques for melisopalynology and then acetolyzed. Frequency classes, frequency of occurrence, pollen richness, importance indexes and pollen diagrams were determined.

Results and conclusions: A total of 53 pollen types were counted at different levels of identification. The best represented families in both immature honey and corbicular pollen from family and species importance index values are: Asteraceae $(3.6 ; 39.2)$ and Myrtaceae $(15.9 ; 26.6)$, while the resources of highest importance in honeys are: Allophylus edulis (13.4), Solanaceae (12.3), Eupatorium type (11.8). In the case of polliniferous resources are: Eupatorium type (30.2), native Myrtaceae type (17.8), Poaceae (8.3). The knowledge generated can be used to value the resource offered by the forest, allowing beekeepers in the area to know and value the dynamics of nectar and pollen flow to the hives.

\section{KEY WORDS}

Honey, honeybee, melissopalynology, pollen, Yungas

\section{REsumen}

Introducción y objetivos: Los principales recursos tróficos empleados por las abejas melíferas son el néctar y el polen, siendo la fuente de carbohidratos y proteína de la colmena respectivamente. En ese contexto, para determinar la relación entre las abejas y los recursos florales, se realizan estudios melisopalinológicos, que permiten identificar las diferentes plantas que contribuyen a la dieta de las abejas.

M\&M: Las muestras se obtuvieron de colmenas de productores de la localidad de Los Toldos (Salta): las de miel inmadura se extrajeron con jeringas esterilizadas de $10 \mathrm{ml}$ y las de polen corbicular a través de trampas caza polen colocadas en la piquera de las colmenas por 24 horas. Todas ellas se procesaron mediante técnicas estándar para melisopalinología con posterior acetólisis. Se determinaron las clases de frecuencia, frecuencia de ocurrencia, riqueza polínica, índices de importancia y diagramas polínicos.

Resultados y conclusión: Se contabilizó un total de 53 tipos polínicos a diferentes niveles de identificación. Las familias mejor representadas tanto en miel inmadura como en polen corbicular a partir de los valores de índice de importancia de familia y especie son: Asteraceae $(3,6 ; 39,2)$ y Myrtaceae $(15,9 ; 26,6)$, mientras que los recursos de mayor importancia en mieles son: Allophylus edulis $(13,4)$, Solanaceae $(12,3)$, Tipo Eupatorium $(11,8)$. En el caso de los recursos poliníferos se encuentran: Tipo Eupatorium $(30,2)$, Tipo Myrtaceae nativas $(17,8)$, Poaceae $(8,3)$. El conocimiento generado, podrá ser utilizado para valorar el recurso ofrecido por el bosque, permitiendo que los apicultores de la zona conozcan y valoren la dinámica del ingreso de néctar y polen a las colmenas.

\section{Palabras claves}

Abeja melífera, Melisopalinología, miel, polen, Yungas 


\section{INTRODUCCIÓN}

Los principales recursos tróficos empleados por las abejas melíferas son el néctar y el polen, siendo la fuente de carbohidratos y proteínas de la colmena, respectivamente. El néctar y el polen son las recompensas más importantes ofrecida por las plantas con flor a los animales que las visitan (Gressler et al., 2006; Nicolson, 2007). El néctar, se define como una solución acuosa y concentrada de azúcares principalmente, además de aminoácidos, iones minerales, sustancias aromáticas, entre otras, secretado por un órgano vegetal especializado llamado nectario, que según la ubicación en la planta puede ser floral o extra floral (Bernardello \& Galetto, 1995). A partir de su recolección, las abejas lo transforman originando la miel, producto biológico muy complejo que varía notablemente en su composición como consecuencia de la flora de origen. Desde su recolección hasta la maduración, el néctar transformado, almacenado y sin opercular, recibe el nombre de miel inmadura (Polaino, 2006). El polen es el gametofito masculino cubierto por dos paredes, una externa denominada exina (de esporopolenina) y otra interna, la intina (constituida de celulosa y pectina); y se encuentra en el interior de las anteras (microsporangios; Font Quer, 2000). Las flores lo ofrecen como recompensa a los visitantes, entre los que se encuentran las abejas melíferas (Apis mellifera L), que lo colectan removiéndolo de las anteras de las flores, lo acopian en sus corbículas (cargas corbiculares) y almacenan en celdas especiales donde se desarrolla un proceso de ensilado para su posterior consumo (Thorp, 2000; De Sá-Otero et al., 2002; Baldi-Coronel et al., 2004; Ramírez \& Montenegro, 2004).

Los bosques subtropicales como las Yungas, son una importante fuente de recursos utilizados como bienes y servicios ecosistémicos. En este contexto, la apicultura cumple un doble rol, ya que contribuye por un lado a la polinización de numerosas especies y a su vez obtiene productos diferenciados como miel, polen, cera, propóleos, entre otros (Quijas et al., 2010; Balvanera, 2012).

Para determinar la relación entre las abejas y los recursos florales, se realizan estudios melisopalinológicos, que permiten identificar las diferentes especies botánicas que contribuyen a la dieta de las abejas (Basilio, 2000; Saya-Rivera \& Huamán Mesía, 2009). En efecto, la caracterización de la flora apícola de una región puede ser usada para determinar el origen botánico y/o geográfico de la miel y polen (Andrada, 2003; Forcone, et al., 2011). Esta información puede ser usada para destacar las especies vegetales significativas para el desarrollo y mantenimiento de la colmena. Existen antecedentes previos en el Noroeste Argentino (Sánchez, 2013; Sánchez \& Lupo 2011; 2016; 2017; Méndez et al., 2014; 2016) para la provincia de Jujuy y en Salta solo se reportan estudios realizados en meliponas, "abejas sin aguijón" (Flores \& Sánchez, 2010; Flores et al., 2015).

En este contexto, el presente trabajo tiene como objetivos identificar los recursos alimentarios utilizados por $A$. mellifera en un área del Bosque subtropical de las Yungas en la provincia de Salta (Argentina) y analizar sus variaciones temporales.

\section{Materiales y Métodos}

\section{Área de estudio}

El Valle de Los Toldos se encuentra en el Dpto. Santa Victoria Oeste, ubicado en el norte de la Provincia de Salta entre los $22^{\circ} 14^{\prime}$ a $22^{\circ} 21^{\prime} \mathrm{S}$ y los $64^{\circ} 39^{\prime}$ a $64^{\circ} 45^{\prime} \mathrm{W}$ aproximadamente. Es una planicie que se encuentra entre los 1500 y $2000 \mathrm{~m}$ s.n.m. En términos fitogeográficos la vegetación representa el piso altitudinal de los Bosques Montanos y su transición hacia los Pastizales de Neblina, distribuidos en parches de bosques mixtos maduros rodeados de bosques secundarios de distinto origen y edad (Brown \& Graw, 1999).

Por encima de los $2000 \mathrm{~m}$ s.n.m. el paisaje está dominado por pastizales naturales junto a bosques de alisos (Brown \& Graw, 1999). El clima es marcadamente estacional con una media de precipitaciones anuales de $1300 \mathrm{~mm}$ concentradas entre los meses de noviembre y abril. La temperatura media anual es de $11,7^{\circ} \mathrm{C}$, la media del mes más frío (julio) es de $5,2^{\circ} \mathrm{C}$ y en el mes más cálido (enero) es de $16,4^{\circ} \mathrm{C}$. Los suelos del área son de desarrollo joven (Brown \& Graw, 1999).

La comunidad de Los Toldos representa una cultura campesina tradicional con una economía básicamente de subsistencia dedicada a la ganadería de trashumancia y la agricultura en las montañas y fondos de valle. Allí se cultiva principalmente maíz y papa, junto a otros productos como maní, ajíes, batata, cayote y yacón (Brown, 2016). En las últimas 


\section{V. Méndez et al. - Recursos tróficos de Apis mellifera L. en las Yungas de Salta}

décadas incrementaron los cultivos de cítricos (naranjas, pomelos, limas) principalmente dirigidos al autoconsumo y mercado local, plantaciones forestales de rápido crecimiento para madera, postes y vigas, entre otros productos. Además, durante los últimos años a través de diferentes programas, se ha buscado desarrollar y fortalecer la economía regional a través de asistencia técnica en diversas áreas, entre ellas la apicultura (Brown \& Graw, 1999).

\section{Obtención y procesamiento de las muestras de miel inmadura}

Las muestras de miel inmadura se obtuvieron a partir de visitas a tres apiarios situados en el área de estudio (para uno de ellos solo se cuenta con una muestra correspondiente al mes de octubre 2014). Las mismas fueron colectadas en cinco colmenas por apiario, seleccionadas a partir de la observación de entrada de néctar y la recomendación del apicultor, a lo largo de los meses de octubre 2014 (cuatro muestras), diciembre 2014 (2), octubre 2016 (2), noviembre 2016 (1) y diciembre 2016 (2), con el uso de jeringas esterilizadas de $10 \mathrm{~cm} 3$ (una por colmena). De esta forma, se obtuvieron un total de 11 muestras, cada una correspondiente a un mes y a un apiario, mediante la homogeneización del contenido de las cinco jeringas en cada uno. Cada muestra tuvo un volumen total de $50 \mathrm{~cm}^{3}$.

El procesamiento de las mieles inmaduras se realizó según la técnica propuesta por Louveaux, et al. (1978) para mieles maduras. Se realizó la dilución de $10 \mathrm{~g}$ de miel en $20 \mathrm{ml}$ de agua destilada a $40^{\circ} \mathrm{C}$ para remover los azucares presentes, con posteriores centrifugaciones a 2000-2500 rpm para concentrar el sedimento polínico y continuar con el proceso de acetólisis (Erdtman, 1960).

Obtención y procesamiento de las muestras de cargas corbiculares

Para la obtención del polen corbicular, se utilizaron trampas caza polen colocadas en la piquera de cinco colmenas seleccionadas al azar del total existente en el apiario, durante 24 horas, una vez al mes durante los meses de diciembre 2014 (2 muestras), enero 2015 (2), octubre 2016 (1), noviembre 2016 (1) y diciembre de 2016 (2) en dos apiarios del área de estudio (Louveaux, 1958; Sayas Rivera \& Huaman Mesía, 2009).

Las muestras cosechadas en cada trampa se unificaron para cada mes y por apiario (ocho en total), y con el uso de un mortero se disgregaron, homogeneizaron, y tomó una alícuota de $0,5 \mathrm{~g}$ del total (Burgos et al., 2015), las que se diluyeron en 10 $\mathrm{cm}^{3}$ de agua destilada a temperatura ambiente y se concentró nuevamente a partir de centrifugaciones a $2500 \mathrm{rpm}$ para proceder a realizar acetólisis (Erdtman, 1960). Cuando fue necesario separar cargas corbiculares aglutinadas a restos vegetales, propóleos, cera y segmentos de abejas, las muestras se diluyeron en alcohol etílico $96 \%$ previamente al proceso de acetólisis.

Análisis microscópico del polen contenido en las muestras

Las observaciones se realizaron con microscopio óptico Zeiss ISC KS2, con una magnificación de 400x y las microfotografías fueron obtenidas mediante el empleo de una cámara digital Leica ICC50 incorporada al microscopio Leica DM 500 con 1000x de magnificación. La identificación de los tipos polínicos se efectuó con el empleo de atlas palinológicos (Markgraf \& D' Antoni, 1978; Heusser, 1971 y Pire et al., 1998; 2002; 2006; 2013) y la confrontación con la Palinoteca de referencia del Laboratorio de Palinología, Facultad de Ciencias Agrarias, UNJu (PAL-JUA). Se aclara que el término "tipo polínico" se refiere a los granos de pólen que por sus características morfológicas difieren entre sí y que, a partir de atlas palinológicos, publicaciones afines y principalmente la confrontación con la Palinoteca de referencia del área de estudio se le asignó una categoría de identificación (especie, género, familia, clase). En aquellos casos en los que no fue posible determinar una categoría, se utilizó el término "tipo" para indicar que el polen tiene semejanza con una especie, género o familia botánica. En el caso del tipo Eupatorium, por sus características palinológicas, reúne a las especies Austroeupatorium inulifolium (Kunth) R.M. King \& H. Rob. y Campovassouria cruciata (Vell.) R.M. King \& H. Rob., dos especies representativas de las Yungas. Otro caso es el del tipo Myrtaceae nativas, que corresponde a las especies de origen nativo de esta familia presentes en las Yungas (Sánchez, 2013). Un caso particular corresponde al tipo Scutia-Condalia que reúne a las especies Scutia buxifolia Reissek y Condalia buxifolia Reissek, también presente en estas áreas boscosas (Sánchez \& Lupo, 2011). 
La nomenclatura de los tipos polínicos se estableció de acuerdo a Joosten \& De Klerk (2002) y De Klerk \& Joosten (2007). Para establecer la riqueza polínica de cada muestra se adaptó el índice de riqueza específica (S) propuesto por Moreno (2001). Por otro lado, para cada tipo polínico identificado, se corroboró el estatus según el Catálogo de Plantas Vasculares del Conosur (Zuloaga et al., 2008).

\section{Análisis de los datos}

Determinación de las clases de frecuencias y frecuencia de ocurrencia:

De cada tipo polínico identificado, tanto en mieles inmaduras como en polen corbicular, se determinaron las clases de frecuencia propuestas por Louveaux et al. (1978), excluyendo en las muestras de miel inmadura aquellos que corresponden a especies de polinización anemófila y sin nectarios. Para ello se contabilizaron por muestra alrededor de 600 granos de polen; con excepción de algunas muestras que presentaron muy bajo contenido polínico y aun contabilizando los pólenes presentes en un nuevo preparado realizado, no se logró reunir esa cantidad. Las clases de frecuencia son las siguientes: Polen predominante (D) $>45 \%$, Polen secundario (S) $16-45 \%$, Polen de menor importancia (M) $3-15 \%$ y Polen traza $(\mathrm{T})<3 \%$.

Por otro lado, también se clasificaron a los recursos identificados en 4 categorías de acuerdo a la frecuencia de ocurrencia en el total de las muestras analizadas, según Feller-Demalsy et al. (1987): Muy Frecuente MF $>50 \%$, Frecuente F 20$50 \%$, Poco Frecuente PF 10-20\%, Raro R $<10 \%$.

\section{Índices de importancia}

Con el objetivo de cuantificar la utilización y/o preferencia de los recursos nectaríferos y poliníferos en el área de estudio, se calcularon los valores de importancia de las familias $\left(\mathrm{IF}_{\mathrm{i}}\right) \mathrm{y}$ de especies ( $\mathrm{IE}_{\mathrm{j}}$ ) propuestas en Nates-Parra et al. (2013), partir de la abundancia relativa (AR) (valor obtenido de la relación entre el conteo del tipo polínico y el total identificado en cada muestra) y la frecuencia de aparición (FA) (número de veces que aparece el tipo polínico en el total de muestras), a través de las siguientes fórmulas:

$\mathrm{IFi}=\Sigma$ Promedio AR especies de $\mathrm{i} *$

$\mathrm{N}^{\circ}$ de muestras i / $\mathrm{N}^{\circ}$ total de muestras Donde i representa la familia botánica.
$\mathrm{IEj}=\Sigma$ Promedio AR especies de $\mathrm{j}$ *

$\mathrm{N}^{\circ}$ de muestras / $\mathrm{N}^{\circ}$ total de muestras

Donde j representa la especie.

\section{Tratamiento estadístico}

A partir del programa RStudio (R Core Team, 2016), se comparó la riqueza polínica utilizada en ambos recursos estudiados a través de una prueba de test de Student para muestras independientes.

Con el fin de indagar sobre la frecuencia, variabilidad, abundancia y variaciones de los recursos tróficos en las muestras tanto de miel inmadura como de polen corbicular a lo largo de los meses muestreados, se elaboró un diagrama polínico y se aplicó un análisis de agrupamiento usando el coeficiente de disimilitud de Edwards \& CavalliSforza. Para ello, utilizando el programa Tilia 2.0.41 (Grimm, 2015), en primera instancia se confeccionó una matriz de datos ingresando en orden cronológico las muestras de miel correspondientes y la variable recursos tróficos identificados. Se retiraron del análisis aquellos tipos con valores inferiores al 3\%, cuya procedencia se considera ocasional en las muestras, provenientes del aire, de residuos polínicos de las celdas de almacenamiento, entre otros.

\section{Resultados}

Se contabilizaron un total de 19 muestras, 11 correspondientes a cosechas de miel inmadura y ocho a polen corbicular. Se identificaron un total de 53 diferentes tipos polínicos: 13 a nivel de categoría especie, 20 a nivel de género, 3 a nivel de tipos, 17 a nivel de familia, uno a nivel de clase botánica (Liliopsida) y un tipo polínico indeterminado (Tabla 1). Del total, el $59 \%$ pertenece a la flora nativa, el $9 \%$ a la flora exótica y el $31 \%$ a flora de origen indeterminado, es decir aquellos recursos que por su nivel de identificación y diversidad no fue posible asignarles un determinado origen (Fig. 1).

Desde el punto de vista estadístico, la riqueza polínica no presentó diferencias significativas entre los dos recursos estudiados (miel inmadura y polen corbicular) (Prueba de t, $\mathrm{t}_{(16)}=0.22, \mathrm{P}>0.05$ ). (Fig. 2). Sin embargo, se puede mencionar que, en los recursos nectaríferos, la riqueza varió entre 4 y 20 tipos polínicos por muestra con un promedio de 12 , y en los poliníferos, entre 6 y 15 tipos polínicos por muestra con un valor promedio igual a 10 . 
M. V. Méndez et al. - Recursos tróficos de Apis mellifera L. en las Yungas de Salta

Tabla 1. Clases de Frecuencia y Frecuencias de Ocurrencia de los recursos polínicos identificados en miel inmadura y polen corbicular en Los Toldos, Salta Argentina. Refencias: D: Dominante, S: Secundario, M: Menor Importancia y T: Traza, FO\%: Frecuencia de ocurrencia.

\begin{tabular}{|c|c|c|c|c|c|c|c|c|c|c|c|c|c|c|c|c|c|c|c|c|c|}
\hline \multirow[b]{2}{*}{ Tipos polinicos } & \multirow[b]{2}{*}{$\frac{0}{\frac{0}{5}}$} & \multirow[b]{2}{*}{$\begin{array}{l}\frac{1}{d} \\
\frac{5}{5} \\
0 \\
0\end{array}$} & \multirow[b]{2}{*}{ 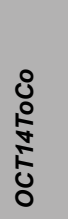 } & \multirow[b]{2}{*}{$\frac{0}{\frac{8}{5}}$} & \multicolumn{4}{|c|}{ Miel inmadura } & \multirow[b]{2}{*}{$\begin{array}{l}\circ \\
\stackrel{0}{0} \\
\stackrel{2}{2}\end{array}$} & \multirow[b]{2}{*}{$\begin{array}{l}\frac{1}{d} \\
\frac{0}{0} \\
\frac{0}{0}\end{array}$} & \multirow[b]{2}{*}{$\begin{array}{l}\frac{0}{0} \\
\frac{0}{0} \\
0\end{array}$} & \multirow[b]{2}{*}{ ઠิํํ } & \multirow[b]{2}{*}{$\frac{\pi}{0}$} & \multirow[b]{2}{*}{$\frac{\pi}{0}$} & \multicolumn{5}{|c|}{ Polen corbicular } & \multirow[b]{2}{*}{$\frac{0}{0}$} & \multirow[b]{2}{*}{ రిํํ } \\
\hline & & & & & $\frac{j}{\frac{j}{0}}$ & $\frac{\frac{0}{\pi}}{\frac{0}{0}}$ & $\begin{array}{l}\frac{1}{d} \\
\frac{1}{0} \\
\frac{5}{0} \\
0\end{array}$ & $\begin{array}{l}\frac{0}{0} \\
\frac{0}{5} \\
0 \\
0\end{array}$ & & & & & & & 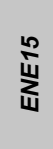 & $\sum_{\text {崫 }}^{n}$ & $\stackrel{0}{\stackrel{5}{0}}$ & $\begin{array}{l}\stackrel{0}{2} \\
\frac{1}{2}\end{array}$ & ¿ัญ & & \\
\hline \multicolumn{22}{|l|}{ Amaranthaceae } \\
\hline Amaranthus & & & & & & & & & & & & & & & M & & & & & & 12,5 \\
\hline Anacardiaceae & & & & & & & & & & & & & & & & & & $\mathrm{T}$ & & & 12,5 \\
\hline Apiaceae & $\mathrm{T}$ & M & T & M & & & & & & & & 36,3 & & & & & & & & & \\
\hline \multicolumn{22}{|l|}{ Aquifoliaceae } \\
\hline Ilex argentina & & T & & & M & M & $\mathrm{T}$ & & $\mathrm{T}$ & & & 45,4 & & & & & & & & & \\
\hline Asteraceae & $M$ & & $T$ & $\mathrm{~T}$ & & & & & & & & 27,2 & & & & & & & & & \\
\hline Baccharis & & & & & M & M & $\mathrm{T}$ & $\mathrm{T}$ & & & & 36,3 & $S$ & & M & M & & & & & 25 \\
\hline Elephatopus mollis & & & & & & & & & & & & & & & $T$ & & & $\mathrm{~T}$ & & & 25 \\
\hline Tipo Eupatorium & & T & M & & $\mathrm{s}$ & $\mathrm{s}$ & & & & & D & 45,4 & $s$ & $\mathrm{~s}$ & $\mathrm{~T}$ & $\mathrm{~T}$ & $\mathrm{~T}$ & D & D & $\mathrm{s}$ & 100 \\
\hline Gnaphalium & & & $T$ & & & & & & & & & 9,1 & & & & & & & & & \\
\hline Senecio & & & & & & & & & & & & & & & & & & $\mathrm{T}$ & M & $\mathrm{T}$ & 37,5 \\
\hline \multicolumn{22}{|l|}{ Berberidaceae } \\
\hline Berberis & $\mathrm{T}$ & $\mathrm{T}$ & & & & $\mathrm{T}$ & & & & & & 27,2 & & $\mathrm{~T}$ & $\mathrm{~T}$ & & T & & & & 37,5 \\
\hline \multicolumn{22}{|l|}{ Betulaceae } \\
\hline Alnus acuminata & + & + & + & & & & & & & & + & 36,3 & & & & & & & & & \\
\hline Bignoniaceae & $T$ & & & & & & & & & & & 9,1 & & & & & & & & & \\
\hline Handroanthus & & $\mathrm{D}$ & & $\mathrm{T}$ & & & & & & & & 18,1 & & & & & & & & & \\
\hline Tecoma & & & $\mathrm{T}$ & & & & & & & & & 9,1 & & & & & & & & & \\
\hline Boraginaceae & $\mathrm{s}$ & $\mathrm{T}$ & $\mathrm{T}$ & $\mathrm{M}$ & $\mathrm{T}$ & $\mathrm{T}$ & $\mathrm{M}$ & & & & & 63,6 & & & & & & & & & \\
\hline Brassicaceae & & & & & & $T$ & & & & & & 9,1 & & & & & & & & & \\
\hline \multicolumn{22}{|l|}{ Buddlejaceae } \\
\hline Buddleja & & & & & & & & & & & & & & M & M & M & & $\mathrm{T}$ & & & 50 \\
\hline Cannabaceae & & & & & & & & & & & & & & & & & & & & & \\
\hline Celtis & + & & + & & + & & & & & & & 27,2 & & & & & & & & & \\
\hline Euphorbiaceae & & & & & & & & & & & & & & & & & & & & & \\
\hline Croton & & T & & $\mathrm{T}$ & & & & & & & & 18,1 & M & M & $\mathrm{Y}$ & M & & M & $\mathrm{T}$ & T & 75 \\
\hline $\begin{array}{l}\text { Sapium } \\
\text { haematospermum }\end{array}$ & & & $\mathrm{T}$ & & & & & & & & & 9,1 & & & & & & & & & \\
\hline Sebastiania & & & D & T & & & $\mathrm{T}$ & & & & & 36,3 & & & & & & & & & \\
\hline Fabaceae & $M$ & $\mathrm{~T}$ & & $M$ & $\mathrm{~T}$ & $T$ & $M$ & $T$ & & & & 63,6 & & & $T$ & & & & & & 12,5 \\
\hline Acacia & & & & & & & & & & & & & & & & & & $\mathrm{T}$ & & & 12,5 \\
\hline $\begin{array}{l}\text { Anadenanthera } \\
\text { colubrina }\end{array}$ & & & & & $\mathrm{T}$ & M & & & & & & 18,1 & & & M & & & & & & 12,5 \\
\hline Mimosa & $\mathrm{T}$ & & & M & & & & & & & & 18,1 & & & & & & & & & \\
\hline $\begin{array}{l}\text { Parapiptadenia } \\
\text { excelsa }\end{array}$ & $\mathrm{T}$ & $\mathrm{T}$ & & $\mathrm{s}$ & & & $\mathrm{T}$ & & & & & 36,3 & & & & & M & & & & 12,5 \\
\hline
\end{tabular}


Bol. Soc. Argent. Bot. 56 (2) 2021

\begin{tabular}{|c|c|c|c|c|c|c|c|c|c|c|c|c|c|c|c|c|c|c|c|c|c|}
\hline \multirow[b]{2}{*}{ Tipos polinicos } & \multirow[b]{2}{*}{$\frac{0}{\frac{8}{5}}$} & \multirow[b]{2}{*}{$\frac{\grave{\delta}}{\frac{j}{8}}$} & \multirow[b]{2}{*}{\begin{tabular}{l}
0 \\
0 \\
\multirow{2}{*}{} \\
$\frac{5}{5}$ \\
0 \\
0
\end{tabular}} & \multirow[b]{2}{*}{$\frac{0}{\frac{5}{5}}$} & \multicolumn{4}{|c|}{ Miel inmadura } & \multirow[b]{2}{*}{$\begin{array}{l}\frac{0}{0} \\
\frac{0}{2} \\
0 \\
2\end{array}$} & \multirow[b]{2}{*}{$\begin{array}{l}\frac{1}{0} \\
\stackrel{0}{0} \\
\frac{0}{0} \\
\frac{0}{0}\end{array}$} & \multirow[b]{2}{*}{$\begin{array}{l}\frac{0}{0} \\
\frac{0}{0}\end{array}$} & \multirow[b]{2}{*}{ ઠ̊ํㄴ } & \multirow[b]{2}{*}{$\frac{⿱}{U}$} & \multirow[b]{2}{*}{$\frac{\mathbb{U}}{0}$} & \multicolumn{5}{|c|}{ Polen corbicular } & \multirow[b]{2}{*}{$\frac{0}{0}$} & \multirow[b]{2}{*}{ ర̊ํㄴ } \\
\hline & & & & & $\frac{\frac{1}{d}}{\frac{d}{d}}$ & $\frac{\circ}{\frac{0}{0}}$ & 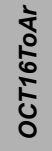 & $\begin{array}{l}0 \\
\frac{0}{0} \\
\frac{5}{0} \\
0\end{array}$ & & & & & & & $\underset{\text { 㞻 }}{\frac{\text { L }}{4}}$ & $\sum_{\frac{w}{w}}^{\frac{n}{w}}$ & $\stackrel{\circ}{\stackrel{\circ}{5}}$ & $\stackrel{0}{2}$ & $\frac{0}{0}$ & & \\
\hline \multicolumn{22}{|l|}{ Juglandaceae } \\
\hline Juglans australis & & + & & + & & & & + & & & & 27,2 & & & & & & & & & \\
\hline Lamiaceae & M & $\mathrm{T}$ & & & & & & $\mathrm{T}$ & & & & 27,2 & & & $\mathrm{~T}$ & & & & & & 12,5 \\
\hline Cantinoa & & & & & & & & & & & & & & & & M & & & & & 12,5 \\
\hline Liliopsida & $\mathrm{T}$ & & & & & & $\mathrm{T}$ & & & & & 18,1 & & $\mathrm{~T}$ & & & & & & & 12,5 \\
\hline Malpighiaceae & & & & & & & & & & & & & & & & & $\mathrm{T}$ & & & & 12,5 \\
\hline Malvaceae & & & & & & & & & & & & & & & & & & $\mathrm{T}$ & & & 12,5 \\
\hline \multicolumn{22}{|l|}{ Moraceae } \\
\hline Morus & & $\mathrm{T}$ & & & & & & & & & & & & & & & & & & & \\
\hline \multicolumn{22}{|l|}{ Myrtaceae } \\
\hline $\begin{array}{l}\text { Blepharocalyx } \\
\text { salicifolius }\end{array}$ & & & & & & & M & M & & & $\mathrm{S}$ & 27,2 & $\mathrm{M}$ & S & $\mathrm{S}$ & & & & & & 37,5 \\
\hline Eucalyptus & $\mathrm{T}$ & & & & & & & & & $\mathrm{D}$ & M & 27,2 & & & & $\mathrm{~S}$ & & & $\mathrm{~T}$ & & 25 \\
\hline $\begin{array}{l}\text { tipo Myrtaceae } \\
\text { nativas }\end{array}$ & $\mathrm{T}$ & & M & M & S & $\mathrm{D}$ & & & & & & 45,4 & & & & & $\mathrm{D}$ & $\mathrm{T}$ & & D & 37,5 \\
\hline \multicolumn{22}{|l|}{ Oleaceae } \\
\hline Ligustrum & & & & & & & & & & & & & & & & $\mathrm{T}$ & $\mathrm{T}$ & & $\mathrm{T}$ & $\mathrm{T}$ & 50 \\
\hline Plantaginaceae & & & & & & & & & & & & & & & & & & & & & \\
\hline Plantago & & & & & & & & & & & & & & & & & & $\mathrm{T}$ & $\mathrm{T}$ & & 25 \\
\hline Poaceae & & & & & & & & & & & & & & $\mathrm{S}$ & $\mathrm{S}$ & $\mathrm{T}$ & & $\mathrm{T}$ & $\mathrm{T}$ & $\mathrm{T}$ & 75 \\
\hline Zea mays & & & & & & & & & & & & & & & $\mathrm{S}$ & M & & & $\mathrm{T}$ & & 37,5 \\
\hline Rhamnaceae & & $\mathrm{T}$ & & & & & & M & S & & & 27,2 & & & & & M & & & & 12,5 \\
\hline $\begin{array}{l}\text { Tipo Scutia- } \\
\text { Condalia }\end{array}$ & & & & & & & S & & & & & 9,1 & & & & & & & & & \\
\hline Rosaceae & M & $\mathrm{T}$ & M & & & $\mathrm{T}$ & M & S & S & $\mathrm{S}$ & & 72,7 & & & & & & & & & \\
\hline Rutaceae & & & & & & & & & & & & & & & & & & & & & \\
\hline Zanthoxylum & $\mathrm{T}$ & $\mathrm{M}$ & M & $\mathrm{T}$ & $\mathrm{T}$ & & $\mathrm{T}$ & $\mathrm{T}$ & M & & & 72,7 & & & & & $\mathrm{~T}$ & & & & 12,5 \\
\hline Salicaceae & & & & & & & & & & & & & & & & & & & & & \\
\hline Salix humboldtiana & $\mathrm{T}$ & $\mathrm{T}$ & $\mathrm{T}$ & $\mathrm{T}$ & & $\mathrm{T}$ & $\mathrm{T}$ & & & & & 54,5 & & & & & & & & & \\
\hline Solanaceae & $S$ & S & & $\mathrm{T}$ & M & $\mathrm{T}$ & $\mathrm{S}$ & M & S & $S$ & & 81,8 & & & & & $\mathrm{~T}$ & M & & $\mathrm{T}$ & 37,5 \\
\hline Vassobia breviflora & & & & & & & & & & & & & & $\mathrm{T}$ & & S & & & & & 25 \\
\hline Sapindaceae & & & & & & & & & & & & & & & & & & & & & \\
\hline Allophylus edulis & M & M & & $\mathrm{S}$ & & M & M & $\mathrm{D}$ & $S$ & $S$ & & 72,7 & & & $\mathrm{~T}$ & & & & & & 12,5 \\
\hline Verbenaceae & & M & & & & & & & & & & 9,1 & & & & & & & & & \\
\hline $\begin{array}{l}\text { Clerodendrum } \\
\text { foetide }\end{array}$ & & & & & & & & & & & & & & & & & & & & $\mathrm{T}$ & 12,5 \\
\hline Vitaceae & & & & & & & & & & & & & & & & & & & & & \\
\hline Cissus & & & & & & & & & & & & & $S$ & M & M & & & $\mathrm{T}$ & $\mathrm{T}$ & $\mathrm{T}$ & 75 \\
\hline Indeterminados & & & & $\mathrm{T}$ & & $\mathrm{T}$ & & & & & & 18,1 & & & & & & & & & \\
\hline Riqueza Polínica & 19 & 20 & 14 & 16 & 10 & 14 & 14 & 10 & 6 & 4 & 4 & & 6 & 9 & 14 & 10 & 10 & 15 & 10 & 9 & \\
\hline
\end{tabular}




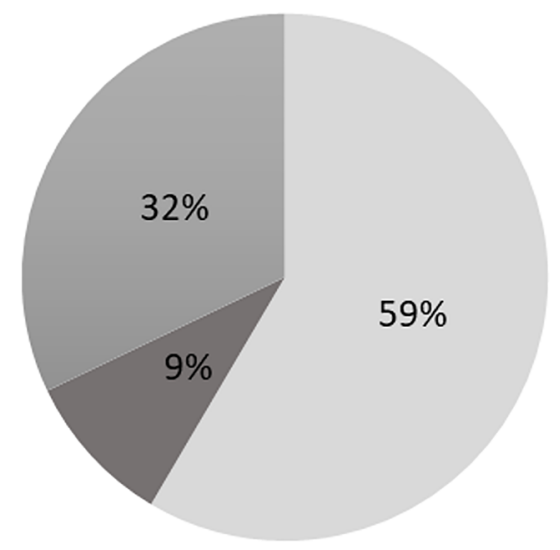

Nativos $\square$ Exóticos $\square$ Indeterminados

Fig. 1. Distribución por estatus de los recursos usados por $A$. mellifera en Los Toldos, Salta Argentina.

En cuanto al índice de importancia de familia (IF $)$ (Fig. 3), se identifican como relevantes en la dieta, tanto nectarífera como polinífera a Asteraceae $(13,6 ; 39,2)$ y Myrtaceae $(15,9 ; 26,6)$. En el caso de los recursos nectaríferos se destacan también las familias Sapindaceae $(13,4)$ y Solanaceae $(12,3)$, mientras que en los poliníferos la familia Poaceae $(12,9)$.

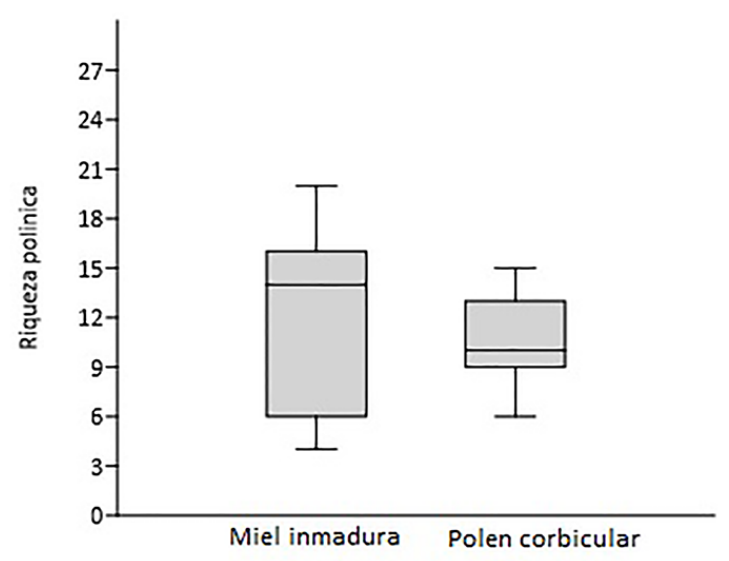

Fig. 2. Boxplot de Riqueza polínica de los recursos usados por $A$. mellifera en Los Toldos, Salta Argentina.

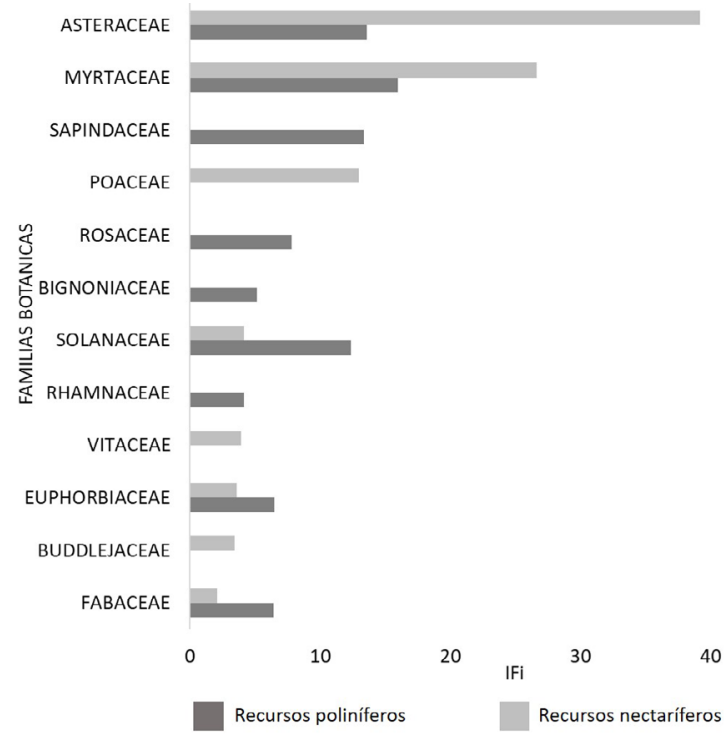

Fig. 3. Índice de importancia de Familias $\left(I_{\mathrm{i}}\right)$ usadas por $A$. mellifera en Los Toldos, Salta Argentina.

Entre los recursos nectaríferos de relevancia a partir de sus mayores valores de $\mathrm{IE}_{\mathrm{j}}$ se encuentran: Allophylus edulis $(13,4)$, Solanaceae $(12,3)$, tipo Eupatorium $(11,8)$, tipo Myrtaceae nativas $(8,3)$, Rosaceae $(7,8)$, Sebastiania $(6,3)$, Handroanthus $(5,1)$ entre otros. En el caso de los recursos poliníferos se encuentra con el mayor índice a tipo Eupatorium (30,2), seguido de tipo Myrtaceae nativas $(17,8)$, Poaceae $(8,3)$, Baccharis $(6,8)$ y Blepharocalyx salicifolius $(6,2)$ (Fig. 4). En la figura 5 se ilustran los principales tipos polinicos identificados.

Deacuerdoalanálisis deagrupamiento efectuado para el ingreso de los recursos poliníferos, se identificaron dos grupos principales, A y B. El grupo A contiene a los meses de diciembre 2014 y enero 2015, caracterizado por el ingreso frecuente de polen de Blepharocalyx salicifolius, Baccharis, Poaceae y Buddleja. Mientras que el grupo B (octubre, noviembre y diciembre de 2016) lo definen la frecuencia y abundancia del recurso tipo Eupatorium y Myrtaceae nativas (Fig. 6).

En el caso del ingreso nectarífero se identificaron dos grupos C y D. El primero se define por los 
Bol. Soc. Argent. Bot. 56 (2) 2021

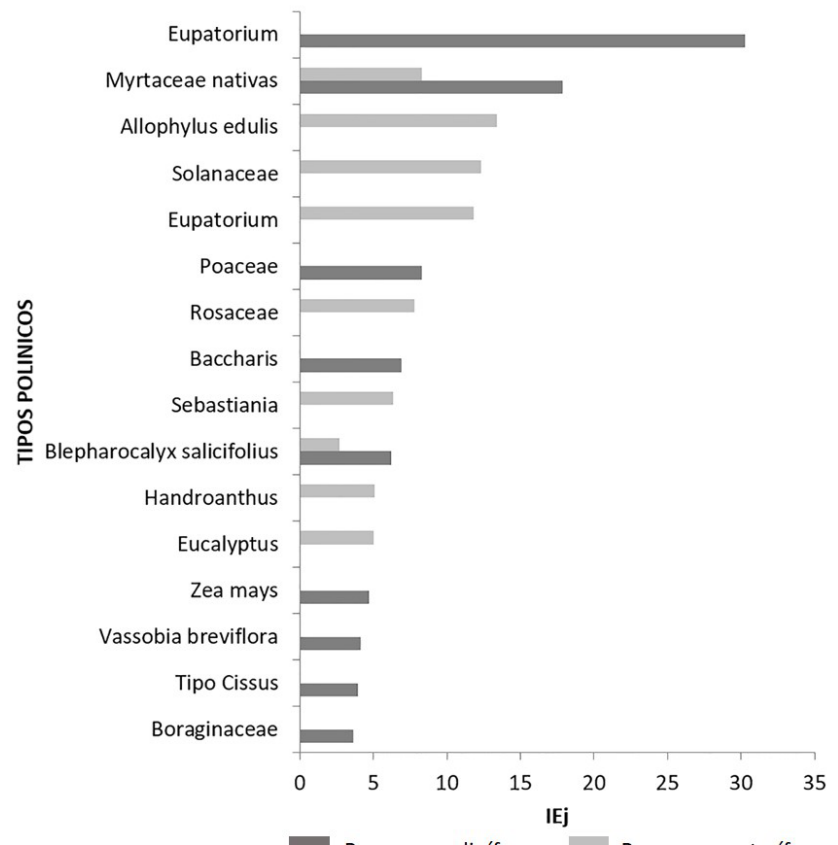

Fig. 4. Índice de importancia de Especies $\left(\mathrm{IE}_{\mathrm{j}}\right)$ usadas por $A$. mellifera en Los Toldos, Salta Argentina.
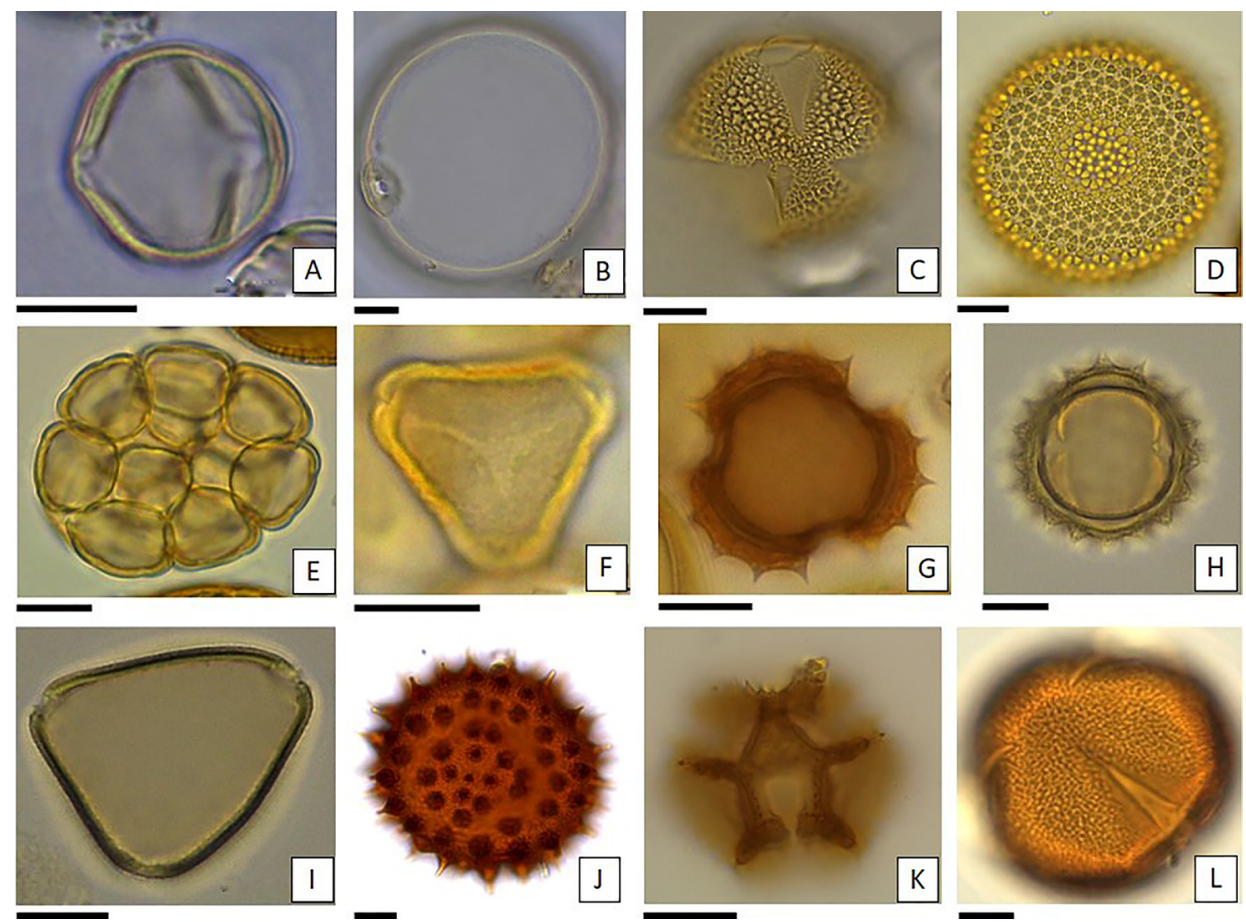

Fig. 5. Tipos polínicos identificados en las muestras de miel inmadura y polen corbicular de $A$. mellifera en la localidad de Los Toldos, Salta (Argentina). A: Solanaceae. B: Poaceae. C: Handroanthus. D: Croton. E: Parapiptadenia excelsa. F: Blepharocalyx salicifolius. G: Baccharis. H: tipo Eupatorium. I: Allophylus edulis. J: Malvaceae. K: Elephantopus mollis: L: Sebastiania. Escalas $=5 \mu \mathrm{m}$. 


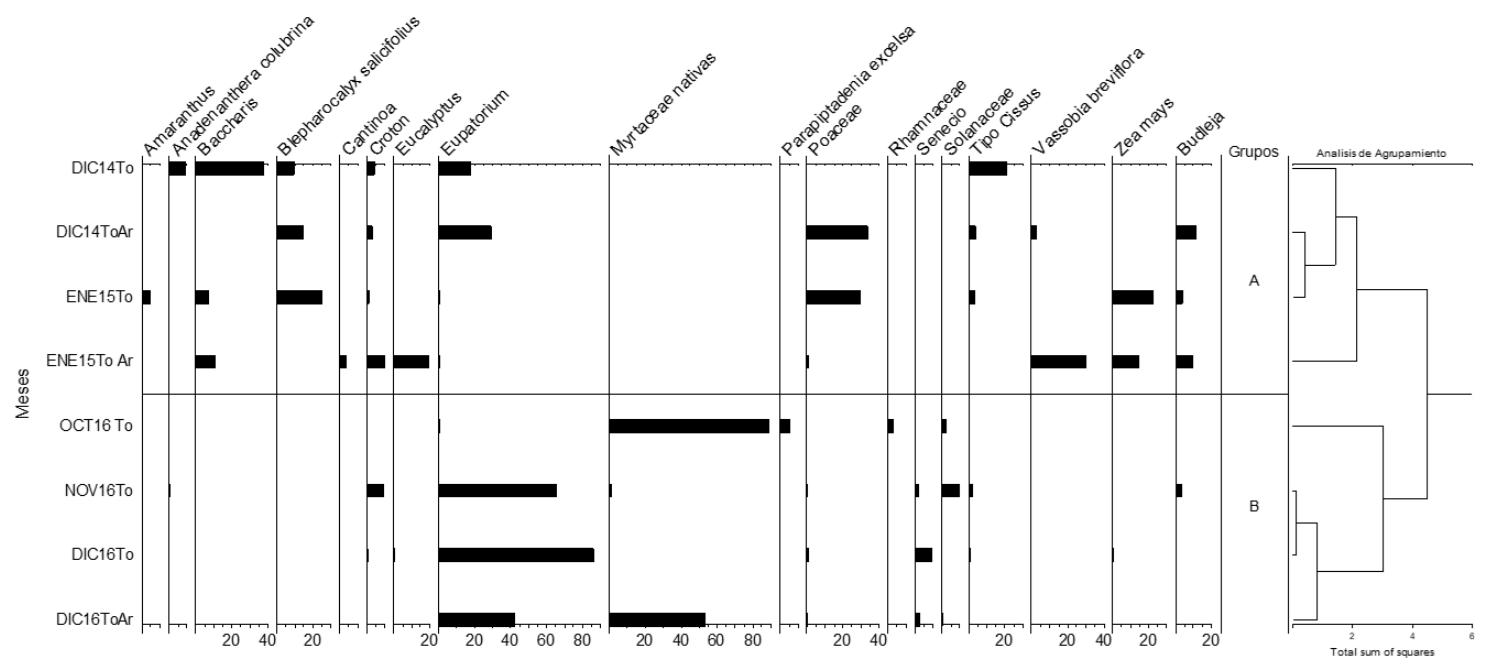

Fig. 6. Diagrama polínico y Análisis de agrupamiento de los recursos poliníferos utilizados por $A$. mellifera en la localidad de Los Toldos, Salta (Argentina) en los meses de diciembre 2014, enero 2015 y octubre-diciembre 2016.

siguientes tipos polínicos, Allophylus edulis, Rosaceae, Fabaceae, Solanaceae y Zanthoxylum, reconociéndose dos subgrupos: C1, que corresponde a las muestras de los meses de diciembre 2014 y enero 2015 y C2 pertenecientes a la campaña 2016-2017. El subgrupo C1 se caracteriza, además de los tipos antes mencionados para el grupo, por Boraginaceae, Myrtaceae, Eupatorium, Asteraceae e Ilex argentina y se registraron dos muestras uniflorales, una de Handroanthus y otra de Sebastiania. El subgrupo C2 presenta, además de aquellos que definen el grupo C, a B. salicifolius, Baccharis, Ilex argentina y Rhamnaceae y no se registraron tipos polínicos dominantes en este subgrupo. Al grupo $\mathrm{D}$, le corresponde una única muestra la del mes de diciembre del 2016 y la caracteriza el tipo Eupatorium como dominante (Fig. 7).

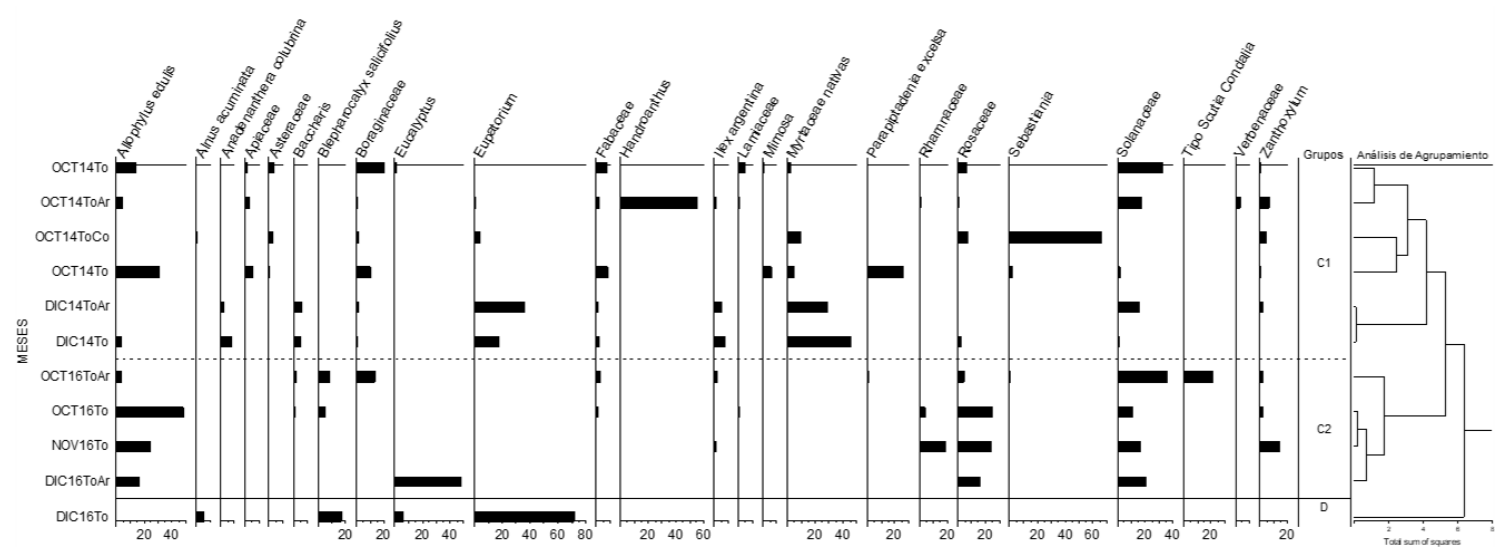

Fig. 7. Diagrama polínico y Análisis de agrupamiento de los recursos nectaríferos utilizados por $A$. mellifera en la localidad de Los Toldos, Salta (Argentina) en los meses de octubre, noviembre y diciembre de 2014 y 2016. 


\section{Discusión}

A partir de la clasificación según su origen, de los tipos polínicos identificados, se observó que los recursos nativos son los más utilizados (Fig. 1). Esta preferencia se ve reflejada en otras áreas subtropicales de Yungas en el noroeste argentino (Méndez et al., 2016; 2018) y en otras zonas del país (Burgos \& Sánchez 2014; Naab \& Tamame, 2007; Salgado et al., 2014;), a diferencia de lo registrado en mieles del Delta inferior del Paraná (Basilio \& Romero, 2002) y el valle inferior del Río Chubut (Forcone et al., 2003), donde existe mayor uso de especies de origen exótico. La preferencia por las especies nativas, estaría relacionada con su abundancia y disponibilidad, que hace que, en lugares como las Yungas, con alta diversidad de especies nativas, las abejas realicen un mayor uso de éstas (Montoya Pfeiffer, 2011).

En el caso de las variaciones en la riqueza polínica de los recursos estudiados, podrían deberse, en el caso del polen corbicular a variables como la oferta de floración donde se encuentran las colmenas y su accesibilidad a ellos determinada por la disposición de las anteras y cantidad del polen en la flor (McLellan, 1976; Pernal \& Currie 2002; Steffan-Dewenter \& Kuhn, 2003). En el caso de la miel inmadura, la variabilidad en la riqueza polínica podría ser explicada por las diferencias en la productividad de néctar, dado que las abejas reconocen aquellas de mayor producción y/o concentración a partir de su disponibilidad (Greggers \& Menzel 1993, Wainselboim \& Farina, 2003). A su vez estas variantes en la producción de néctar de las distintas especies dependen de factores ambientales como las precipitaciones y la temperatura que influencian la humedad del suelo (Sandoval, 2020).

En cuanto al índice de importancia de familia $\left(\mathrm{IF}_{\mathrm{i}}\right)$ (Fig. 3), las más relevantes en la dieta, tanto nectarífera como polinífera son Asteraceae $(3,6$; $39,2)$ y Myrtaceae $(15,9 ; 26,6)$. En el caso de los recursos pertenecientes a la familia Asteracea son importantes proveedores de recursos apícolas no solo por la gran diversidad de especies y distribución cosmopolita (Del Vitto \& Petenatti 2009), sino particularmente porque presentan una unidad ecológica que atrae polinizadores, sobre todo por el efecto visual producido por flores reunidas en densas y conspicuas inflorescencias (capítulos). Así, el néctar y el polen ofrecido a los visitantes florales están reunidos en un espacio reducido, facilitando la tarea y optimizando el consumo energético (Del Vitto \& Petenatti, 2015). Los recursos de importancia identificados en esta familia corresponden a tipo Eupatorium $\left(\mathrm{IE}_{\mathrm{j}}=11,8 ; 30,2\right)$ y Baccharis $(6,8)$. En relación a ello, la presencia y abundancia del tipo Eupatorium, que abarca a dos especies arbustivas (Austroeupatorium inulifolium y Campovassouria cruciata) se encuentran formando parte del sotobosque y áreas disturbadas cercanas a los apiarios estudiados (obs pers.). Su importancia reside en la selección de estos recursos por parte de las colmenas que responden a una oferta de fuentes accesibles y abundantes en el ambiente (Fagúndez, 2011; Montoya Pfeiffer, 2011). Asimismo, se destaca su importancia como un recurso nectarífero para $A$. mellifera en otros sectores de las Yungas, (Sánchez, 2013; Méndez et al., 2016; Sánchez \& Lupo, 2017).

La importancia de la familia Myrtaceae $(15,9$; 26,6), representada por los recursos Blepharocalyx salicifolius y tipo Mirtacaea nativa, podría explicarse a partir de los siguientes aspectos: 1) Es una familia muy diversa en América del Sur (Wilson et al., 2001), formando parte importante de las Yungas, ya que junto con las Lauraceae definen la Selva Montana en las Yungas (Cabrera, 1976; Brown et al., 2002). 2) Por su estructura floral son muy atractivas a los polinizadores (Gressler et al., 2006), siendo visitadas tanto para la obtención de polen, como de néctar, según lo demuestran los análisis melisopalinológicos realizados en mieles de $A$. mellifera (Méndez, 2014; Méndez et al., 2018; Sánchez, 2013; Sánchez \& Lupo, 2017). También son recursos de importancia para las "abejas sin aguijón" (Meliponini) en las Yungas en Salta (Flores \& Sánchez, 2010; Flores et al., 2015) y para otras zonas neotropicales (Ramalho et al., 1990), confirmando según los planteado por Ramalho (2004) la preferencia de las abejas por los recursos arbóreos de floración masiva, condición característica de esta familia botánica.

En relación a los recursos nectaríferos, otra de las familias de importancia es Sapindaceae $(12,9)$, que presenta una distribución tropical y subtropical en el mundo (Acevedo-Rodríguez et al., 2011) y en el noroeste de Argentina se 


\section{V. Méndez et al. - Recursos tróficos de Apis mellifera L. en las Yungas de Salta}

encuentran en los bosques de Yungas siendo el principal representante Allophylus edulis (A. St.-Hil., A. Juss. \& Cambess.) Hieron. ex Niederl. (Cabrera, 1976; Brown et al., 2002). Esta especie arbórea se caracteriza por ser unos de los principales aportes $\left(\mathrm{IE}_{\mathrm{j}}=13,4\right)$ para las colmenas en estudio. Resultados similares se observan en los inicios de la temporada apícola para los bosques de Yungas en el sector Oeste de Jujuy (Méndez et al., 2016); registrándose su presencia también en mieles maduras uniflorales de A. mellifera (Sánchez, 2013; Sánchez \& Lupo, 2017) y de Plebeia intermedia en la localidad de Baritú (Flores et al., 2015). Esta especie cumple con las características de floración masiva propuesta por Ramalho (2004), debido a que presenta inflorescencias con alta densidad de flores, considerado como un aspecto de selección del recurso melífero por parte de las abejas. Además, en otras áreas tropicales como el sureste de Brasil, otras especies de este género, también son importantes recursos melíferos (Almeida Braga et al., 2012).

La familia Solanaceae $(13,4)$ se caracteriza por su amplia distribución cosmopolita (Barboza, 2013). En el área de estudio durante la época estival los representantes herbáceos principalmente colonizan el sotobosque de los ambientes más prístinos o bien en áreas disturbadas cercanas a las colmenas (obs. pers.). Es por ello que la presencia de estos recursos polínicos se relacionaría con la abundante disponibilidad del recurso floral (Montoya Pfeiffer, 2011).

En relación a Poaceae $(12,9)$, corresponde a una familia cosmopolita que normalmente es considerada como anemófila. Sin embargo, en estudios recientes se han registrado insectos visitantes, entre ellos abejas (Wolowski \& Freitas, 2015; Saunders, 2018) y se ha identificado a los recursos de esta familia, como una importante fuente de proteínas (polen) para las colmenas en Chile (De Sá-Otero et al., 2009). Entre los recursos poliníferos identificados en el área de estudio se encuentran Poaceae y Zea mays. Su presencia en las cargas corbiculares, se podría relacionar, además de la calidad nutricional, con la gran producción de polen por inflorescencia que permite tener recursos disponibles para el forrajeo (Prieto-Baena et al., 2003). Además, en los alrededores de Los Toldos, se encuentran numerosos cultivos de maíz a pequeña de escala para autoabastecimiento o comercialización local (Brown, 2016). Mientras que en la miel inmadura correspondería a una contaminación con el polen corbicular almacenado en las colmenas.

En este estudio se observa la importancia nectarífera y polinífera de la familia Euphorbiaceae $(6,4 ; 3,5)$ para la zona de estudio, coincidiendo con lo hallado por Sánchez (2013) y Méndez et al. (2016), quienes destacan su importancia en mieles madura e inmaduras de Jujuy. En áreas tropicales de Bolivia esta familia es de uso muy frecuente por Tetragonisca angustula (Saravia-Nava et al., 2018). Posiblemente su relevancia reside en la gran diversidad de especies presentes en hábitats neotropicales (Ramalho et al., 1990) como en el norte de Argentina (Zuloaga, 1999), donde se encuentran especies de los géneros Acalypha, Croton, Euphorbia, Jatropha, Sebastiania y Manihot, entre otras, como fuentes de polen y néctar accesibles para las colmenas.

Se cita por primera vez la importancia nectarífera del recurso Handroanthus, este género arbóreo es ampliamente distribuido desde el noroeste de México al noroeste de Argentina. Exhibe una fenología de floración en masa común en los bosques estacionales (Souza et al., 2004) característica de preferencia en los apidos (Ramalho, 2004). Si bien los legítimos polinizadores de este género corresponden principalmente a especies de las tribus Centridini y Euglossini, la presencia de este recurso en mieles inmaduras para la región en estudio podría relacionarse con un efecto oportunista al igual que otros polinizadores que roban el néctar de sus flores cortadas en la base (Schlindwein et al., 2014)

De acuerdo al análisis de agrupamiento efectuado tanto para el ingreso de los recursos poliníferos como nectaríferos, se identificaron grupos y sub grupos que responden a los años donde se recolectaron las muestras. Esta diferenciación en general coincide con los periodos de floración de las especies identificadas. A su vez es importante tener en cuenta que la fenología reproductiva depende de una compleja interacción entre factores endógenos y exógenos, donde los factores climáticos de mayor influencia son el fotoperiodo, la temperatura y la precipitación (Smith-Ramirez \& Armesto, 1994) 


\section{Conclusiones}

En el trabajo realizado, se caracterizan por primera vez los recursos tróficos utilizados por $A$. mellifera en este sector de las Yungas, donde los pequeños productores tienen la posibilidad de obtener mieles diferenciadas para el mercado regional.

Del análisis realizado en este trabajo, se observa tanto en mieles inmadura como en polen corbicular, la influencia de la flora nativa perteneciente al distrito de la Selva Montana de las Yungas.

Entre los recursos tróficos identificados en la zona, se destacan: tipo Eupatorium, Myrtaceae nativas, Allophylus edulis, Solanaceae, Baccharis, Blepharocalyx salicifolius, Poaceae y Handroanthus, constituyendo la asociación polínica característica del área de estudio.

El conocimiento generado, podrá ser utilizado para valorar el recurso ofrecido por el bosque, permitiendo comprender a los apicultores del sector las variaciones del ingreso nectarífero y polinífero a las colmenas.

La identificación de los recursos poliníferos y sus variaciones durante la temporada apícola sientan las bases para la realización de estudios de índole nutricional y sanitario de las colmenas.

\section{Contribución DE los autores}

El trabajo corresponde a uno de los sitios trabajados en el marco de una Tesis Doctoral dirigida por la Dra. Ana Carina Sánchez y Co dirigida por la Dra. Liliana Concepción Lupo. Todos los autores contribuyeron en la colecta de datos, su interpretación y redacción del manuscrito.

\section{Agradecimientos}

Las autoras agradecen al Consejo Nacional de Investigaciones Científicas y Tecnológicas (CONICET) y a la Universidad Nacional de Jujuy por el financiamiento para el desarrollo de las actividades de investigación, a la fundación Pro Yungas por el contacto con productores apícolas de la localidad de Los Toldos (Salta, Argentina) y particularmente a los productores por la buena predisposición para la toma de muestras y la capacitación en el manejo de la actividad.

\section{Bibliografía}

ACEVEDO-RODRÍGUEZ P., VAN WELZEN PC, ADEMA F., VAN DER HAM RWJM. 2010 Sapindaceae. En: KUBITZKI K. (eds) Flowering Plants. Eudicots. The Families and Genera of Vascular Plants, vol 10, pp 357-407. Springer, Berlín, Heidelberg. https://doi.org/10.1007/978-3-642-14397-7_17

ALMEIDA BRAGA, J., É. OLIVEIRA SALES, J. SOARES NETO, M. MENEZES CONDE, O. M BARTH, O. M., \& LORENZON, M. C. 2012. Floral sources to Tetragonisca angustula (Hymenoptera: Apidae) and their pollen morphology in a Southeastern Brazilian Atlantic Forest. Rev. Biol. Trop. 60: 1491-1501

ANDRADA A. C. 2003. Flora utilizada por Apis mellifera L. en el sur del Caldenal (Provincia Fitogeográfica del Espinal), Argentina. Rev. Mus. Argent. Cs. Nat., N. S. 5: 329-336.

BALDI-CORONEL, B., D. GRASSO, S. CHAVES PEREIRA \& G. FERNÁNDEZ. 2004. Caracterización bromatológica del polen apícola argentino. Ciencia, Docencia y Tecnología 15: 145181.

BALVANERA, P. 2012. Los servicios ecosistémicos que ofrecen los bosques subtropicales. Ecosistemas. 21: $136-147$.

BARBOZA, G. 2013. Dicotyledoneae-Solanaceae. En: ZULOAGA F. O. \& M. J. BELGRANO (eds.). Flora vascular de la República Argentina. Instituto de Botánica Darwinion. República Argentina.

BARTH, M.O. \& M. C. LORENZON. 2012. Floral sources to Tetragonisca angustula (Hymenoptera: Apidae) and their pollen morphology in a Southeastern Brazilian Atlantic Forest. Rev. Biol. Trop. 60: 1491-1501.

BASILIO, A. M. 2000. Cosecha polínica por Apis mellifera (Hymenoptera) en el bajo Delta del Paraná: comportamiento de las abejas y diversidad del polen. Rev. Mus. Argent. Cs. Nat., N. S. 2: 111-121.

BASILIO, A. M. \& E. J. ROMERO. 2002. Variaciones anuales y estacionales en el contenido polínico de la miel de un colmenar. RIA 31: 41 - 58.

BERNARDELLO, L., \& GALETTO, L. 1995. Néctar: la realidad del mito. Ciencia hoy 5: 35-40.

BROWN A. D. \& GRAW A. G. 1999. Fortalecimiento de la diversidad productiva bajo condiciones de sustentabilidad (municipio de Los Toldos, Salta, Argentina). Programa Estratégico de acción para la cuenca del rio Bermejo. 138 pp. 


\section{V. Méndez et al. - Recursos tróficos de Apis mellifera L. en las Yungas de Salta}

BROWN A. D. 2016. Reserva de biosfera de las Yungas: paisajes y pueblos de montaña del NOA. 1a ed. - Del Subtrópico. Yerba Buena, Tucumán, Argentina.

BROWN, A. D., A. GRAU, T. LOMÁSCOLO, \& N. IGNACIO. 2002. A conservation strategy for subtropical montane forests (Yungas) in Argentina. Ecotropicos 15: 147-159.

BURGOS, M. G., A. C. SÁNCHEZ, \& L. C. LUPO 2015. Análisis polínico de cargas corbiculares del Chaco Serrano, Jujuy (Argentina). Lilloa 52: 3-11.

CABRERA, A. L. (1976). Regiones Fitogeografias Argentinas. Enciclopedia Argentina de Agricultura y Jardinería. Ed. Acme. Buenos Aires.

DE KLERK, P., \& H. JOOSTEN. 2007. The difference between pollen types and plant taxa: a plea for clarity and scientific freedom. E\&G Quaternary Science Journal 56: 162-171. https://doi.org/10.3285/eg.56.3.02

DE SÁ-OTERO, M. P., A. GONZÁlEZ, M. RODRÍGUEZ-DAMIÁN, \& E. CERNADAS. 2004. Computer-aided identification of allergenic species of Urticaceae pollen. Grana 43: 224-230. https://doi.org/10.1080/00173130410000749

DEL VITTO, L. A., \& E. M. PETENATTI. 2009. Asteráceas de importancia económica y ambiental: Primera parte. Sinopsis morfológica y taxonómica, importancia ecológica y plantas de interés industrial. Multequina 18: 87-115.

DEL VitTO, L. A., \& E. M. PETENATTI. 2015. Asteráceas de importancia económica y ambiental: Segunda parte: Otras plantas útiles y nocivas. Multequina 24: 47-74.

ERDTMAN, G. 1960. The acetolysis method. Svensk. Bot. Tidskr. 54: 561-564.

FELLER DEMALSY, M., J. PARENT, \& A. STRACHAN. 1987. Microscopic analysis of honeys from Alberta, Canada. J. Apic. Res. 26: 123-132. https://doi.org/10.1080/00218839.1987.11100748

FLORES, F. F., \& A. C. SÁNCHEZ. 2010. Primeros resultados de la caracterización botánica de mieles producidas por Tetragonisca angustula (Apidae, Meliponinae) en Los Naranjos, Salta, Argentina. Bol. Soc. Argent. Bot. 45: 81-91.

FLORES F. F., LUPO, L. C. \& N. I. HILGERT. 2015. Recursos tróficos utilizados por Plebeia intermedia (Apiade, Meliponini) en la localidad de Baritú, Salta, Argentina. Caracterización botánica de sus mieles. Bol. Soc. Argent. Bot. 50: 515-529.

FORCONE A., BRAVO O. \& M. G. AYESTARAN. 2003. Interaannual variation in the pollinic spectrum of honey from the lower valley of the River
Chubut (Patagonia, Argentina). Spanish Journal of Agricultural Research 1: 29-36.

FORCONE, A., ALOISI, P. V. RUPPEL, S.\& M. MUÑOZ. 2011. Botanical composition and protein content of pollen collected by Apis mellifera L. in the north-west of Santa Cruz (Argentinean Patagonia). Grana 50: 30-39. https://doi.org/10.1080/00173134.2011.552191

GREGGERS, U., \& R. MENZEL. 1993. Dinámica de la memoria y estrategias de alimentación de las abejas. Behav Ecol Sociobiol. 32: 17-29. https://doi.org/10.1007/BF00172219.

GRESSLER, E., M. A., PIZO, \& L. P. C. MORELLATO. 2006. Polinização e dispersão de sementes em Myrtaceae do Brasil. Rev. bras. Bot. 29: 509-530.

GRIMM, E. C. (2015). Tilia software (v. 2.0.41). Illinois State Museum. Springfield, Illinois.

HEUSSER, C. J. 1971. Pollen and Spores of Chile. Tucson. Arizona.

JOOSTEN, H., \& P. DE KLERK. 2002. What's in a name? Some thoughts on pollen classification, identification, and nomenclature in Quaternary palynology. Review of Palaeobotany and Palynology 122: 29-45.

https://doi.org/10.1016/S0034-6667(02)00090-8

LOUVEAUX, J. 1958. Recherchessur la récolte du pollen par les abeilles (Apis mellifica L). Les Annales de l'Abeille 1: 113-188.

LOUVEAUX, J., A. MAURIZIO, \& G. VORWHOL. 1978. Methods of Melisopalinology. Bee World. 59: 139-157. https://doi.org/10.1080/0005772X.1978.11097714

MARKGRAF, V., \& D’ANTONI, H. 1978. Pollen Flora of Argentina. Tucson, Arizona, EE.UU: The University of Arizona Press.

MCLELLAN, A.R., 1976. Factors Affecting Pollen Harvesting by the Honeybee. Journal of Applied Ecology. 13: 801-811. https://doi.org/10.2307/2402256

MÉNDEZ, M. V., A. C. SÁNCHEZ, F. F. FLORES, \& L. C. LUPO. 2016. Análisis polínico de mieles inmaduras en el sector Oeste de las Yungas de Jujuy (Argentina). Bol. Soc. Argent. Bot. 51: 449-462.

MÉNDEZ, M., A.C. SÁNCHEZ, F.F. FLORES, \& L.C. LUPO. 2018. Recurso polinífero utilizado por Apis mellifera L. (Himenoptera: Apidae) en un área de bosque subtropical del noroeste de Argentina. Rev. Biol. Trop. 66: 1182-1196.

http://dx.doi.org/101551/rbt.v66i3.30856

MONTOYA PFEIFFER, P. M. 2011. Uso de recursos florales poliniferos por Apis mellifera (Hymenoptera: Apidae) en apiarios de la Sabana de Bogotá 
$y$ alrededores. Tesis de Maestria. Universidad Nacional de Colombia.

MORENO, C. E. 2001. Métodos para medir la biodiversidad. Zaragoza, España: M\&T-Manuales y Tesis SEA.

NAAB, O. \& M. A. TAMAME. 2007. Flora apícola primaveral en la región del Monte de la provincia de la Pampa (Argentina). Bol. Soc. Argent. Bot. 42: 251-259.

NATES-PARRA, G., P. MONTOYA, F. J. CHAMORRO, N. RAMÍREZ, C. GIRALDO, \& D. OBREGÓN. 2013. Origen geográfico y botánico de mieles de Apis mellifera (Apidae) en cuatro departamentos de Colombia. Acta Biológica Colombiana 18: 427438.

NICOLSON, S. W. 2007. Chapter 7: Nectar consumers. In: NICOLSON S. W., NEPI M. \& E. PACINI. (eds.), pp. 289 - 344. Springer. The Netherlands.

PERNAL, S. F., \& R. W. CURRIE. 2002. Discrimination and preferences for pollen-based cues by foraging honeybees, Apis mellifera L. Animal Behaviour 63: 369-390. https://doi.org/10.1006/anbe.2001.1904

PIRE, S. M., ANZÓTEGUI, L. M. \& CUADRADO, G. A. 1998. Flora Polínica del Nordeste Argentino 1. EUDENE-UNNE Corrientes, Argentina.

PIRE, S. M., L. M. ANZÓTEGUI \& G. A. CUADRADO. 2002. Flora Polínica del Nordeste Argentino 2. EUDENE-UNNE. Corrientes, Argentina.

PIRE, S. M., L. M. ANZÓTEGUI \& G. A. CUADRADO. 2006. Flora Polínica del Nordeste Argentino 3. EUDENE-UNNE. Corrientes, Argentina.

PIRE, S. M., L. M. ANZÓTEGUI \& G. A. CUADRADO. 2013. Flora Polínica del Nordeste Argentino 4. EUDENE-UNNE. Corrientes, Argentina.

POLAINO, C. 2006. Manual práctico del apicultor. Editorial Cultural. Madrid, España.

PRIETO-BAENA J. C., P. J. HIDALGO., E. DOMÍNGUEZ \& C. GALÁN. 2003. Pollen production in the Poaceae family. Grana 42: 153159.

RAMALHO, M. 2004. Stingless bees and mass flowering trees in the canopy of Altlantic Forests: a tight relationship. Acta Bot. Bras. 18: 37-47. https://doi.org/10.1590/S0102-33062004000100005

RAMALHO, M. A., A. KLEINERT-GIOVANNINI, \& V. IMPERATRIZ-FONSECA. 1990. Important bee plants for sting-less bees (Melipona and Trigonini) and Africanized honeybees (Apis mellifera) in neotropical habitats: a review. Apidologie 21: 469488. https://doi.org/10.1051/apido:19900508
RAMÍREZ, R. \& G. MONTENEGRO. 2004. Certificación del origen botánico de miel y polen corbicular pertenecientes a la comuna de Litueche, VI Región de Chile. Ciencia e Investigación Agraria 31: 197-211.

R Core Team (2016). R: A language and environment for statistical computing. R Foundation for Statistical Computing, Vienna, Austria. URL https://www.Rproject.org/

SALGADO C. R., G. PIESKO \& M. C. TELLERIA. 2014. Aporte de la melisopalinología al conocimiento de la flora melífera de un sector de la Provincia Fitogeográfica Chaqueña. Bol. Soc. Argent. Bot. 49: 513-524.

SANCHEZ, A. C. 2013. Caracterización Botánica y Geográfica de las mieles de Apis mellifera $L$. en la Provincia de Jujuy. Tesis Doctoral. Facultad de Ciencias Naturales. Universidad Nacional de Salta.

SÁNCHEZ, A. C., \& L. C. LUPO. 2011. Origen botánico y geográfico de las mieles de El Fuerte, Departamento de Santa Bárbara, Jujuy, Argentina. Bol. Soc. Argent. Bot. 46: 105-111.

SÁNCHEZ, A. C., \& L. C. LUPO. 2017. Pollen analysis of honeys from the northwest of Argentina: Province of Jujuy. Grana. 56: 462-474. https://doi.org/10.1080/00173134.2017.1284260

SANDOVAL C. Y. 2020. Influencia del clima en la variación temporal de dos recursos apícolas nativos de las Yungas: Allophylus edulis y Blepharocalyx salicifolius en la localidad de Tilquiza, Jujuy, Argentina. Tesina de Grado. Facultad de Cs. Agrarias. Universidad Nacional de Jujuy.

SA-OTERO M. P., S. MARCIAL BUGARIN, S. ARMESTO BATZAN, \& E. DIAZ LOSADA. 2002. Método de determinación del origen geográfico del polen apícola comercial. Lazaroa 23: 25-34.

SARAVIA-NAVA, A., H. M. NIEMEYER \& C. F. PINTO. 2018. Tipos de polen utilizados por la abeja sin aguijón nativa, Tetragonisca angustula (Latreille), en un bosque de transición AmazonasChiquitano de Bolivia. Entomología neotropical 47: 798-807.

SAUNDERS M. E. 2018. Insect pollinators collect pollen from wind-pollinated plants: implications for pollination ecology and sustainable agriculture. Insect Conservation and Diversity 11: 13-31. https:// doi.org/10.1111/icad.12243

SAYAS RIVERA, R. \& L. HUAMÁN MESÍA. 2009. Determinación de la flora polinífera del valle de Oxapampa (Pasco-Perú) en base a estudios palinológicos. Ecología aplicada 8: 53-59. 


\section{V. Méndez et al. - Recursos tróficos de Apis mellifera L. en las Yungas de Salta}

SCHLINDWEIN, C., C. WESTERKAMP, A. T. CARVALHO, \& P. MILET-PINHEIRO. 2014. Visual signalling of nectar-offering flowers and specific morphological traits favour robust bee pollinators in the mass-flowering tree Handroanthus impetiginosus (Bignoniaceae). Bot. J. Linn. Soc. 176: 396-407. https://doi.org/10.1111/boj.12212

SMITH-RAMIREZ, C. \& J. J. ARMESTO. 1994. Flowering and Fruiting Patterns in the Temperate Rainforestcof Chiloé, Chile - Ecologies and Climatic Constraints. Journal of ecology 82: 353 365. https://doi.org/10.2307/2261303

SOUZA, D. D. S., M. LENZI, \& A. I. ORTH. 2004. Contribuição à ecologia da polinização de Tabebuia pulcherrima (Bignoniaceae) em área de restinga, no sul de Santa Catarina. Biotemas 17: 47-66.

STEFFAN-DEWENTER, I., \& A. KUHN. 2003. Honeybee foraging in differentially structured landscapes. Proceedings of the Royal Society of London B: Biological Sciences 270: 569-575.

THORP, W. R. 2000. The collection of pollen by bees (Apoidea). Plant Systematic and Evolution. 222: 211-223. https://doi.org/10.1098/rspb.2002.2292

WAINSELBOIM, A. J., \& W. M. FARINA. 2003. Trophallaxis in honeybees, Apis mellifera (L.), as related to their past experience at the food source. Animal behaviour 66: 791-795. https://doi.org/10.1006/anbe.2003.2256

WILSON, P. G., M. M. O’ BRIEN, P. A. GADEK, \& C. J. QUINN. 2001. Myrtaceae revisited: a reassessment of infrafamilial groups. Am. J. Bot.. 88: 2013-2025. https://doi.org/10.2307/3558428

WOLOWSKI M \& L. FREITAS. 2015. An overview on pollination of the Neotropical Poales. Rodriguésia. 66: 329-336.

http://dx.doi.org/10.4590/2175-7860201566204

ZULOAGA, F. O. 1999. Catálogo de las plantas vasculares de la República Argentina II. FabaceaeZygophyllaceae (Dicotyledoneae). En: F. ZULOAGA \& O. MORRONE (eds.), Catálogo de las Plantas Vasculares del Cono Sur, pp. 623-1269. The Missouri Botanical Garden Press, USA.

ZULOAGA, F. O., O. N. MORRONE, M. J. BELGRANO, C. MARTICORENA \& E. MARCHESI. (eds). 2008. Catálogo de las Plantas Vasculares del Cono Sur (Argentina, Sur de Brasil, Chile, Paraguay y Uruguay). Monogr. Syst. Bot. Missouri Bot. Gard. 107: I-XCVI, 1-983; 107: I-XX, 985-2286; 107: I-XXI, 2287-3348 [online]. Disponible en: http:// www2.darwin.edu.ar/Proyectos/FloraArgentina/ FA.asp [Acceso: 2 Agosto 2020]. 
